\title{
Pengaruh ekstrak minyak cumi pada umpan bubu terhadap hasil tangkapan kepiting bakau dan rajungan di Perairan Malise Kecamatan Tabukan Tengah
}

\author{
The effect of squid oil extract on trap baits toward the catch of mangrove crab and swimming \\ crab in Malise waters of Tabukan Tengah District
}

\author{
MAICHEL ARVAN PANANGGUNG*, IVOR L. LABARO dan EMIL REPPIE \\ Program Studi Pemanfaatan Sumberdaya Perikanan, Fakultas Perikanan dan Ilmu Kelautan, \\ Universitas Sam Ratulangi, Manado 95115
}

\begin{abstract}
Mangrove crab (Scylla serrata) and swimming crab (Portunus pelagicus) are economically important marine commodities produced from the coastal waters of Sangihe Islands Regency. But those marine commodity products are usually only caught accidentally with a bottom gill net. There has been a special trap fishing gear for that resources, but not known well by local fishermen. Addition of squid oil extraction baits could increase the fishing power of mangrove crab and swimming crab traps. This research aims to study the effect of squid oil extract on traps bait to catch mangrove crab and swimming crab; and identify the types of biota captured. This research was done in coastal waters of Malise village, Tabukan Tengah District of Sangihe Islands Regency for 2 weeks September 2015; based on experimental method. Six unit traps were operated ten trips where three units of them used scad mackerel bait that injected with squid oil extract, and tree other units just used scad mackerel bait without extract; and the capture data were analyzed using t test. The catch was 142 individuals (135 mangrove crabs and 7 swimming crab); where 86 crabs was caught by scad mackerel bait with squid oil extract, and 56 crabs caught with bait without squid oil extract. The analysis showed that the use of squid oil extracts on trap baits increased the catch.
\end{abstract}

Keywords: mangrove crab, swimming crab,trap baits, squid oil extract, Sangihe

\begin{abstract}
ABSTRAK
Kepiting bakau (Scylla serrata) dan rajungan (Portunus pelagicus) merupakan komoditi hasil laut ekonomis penting yang dihasilkan dari perairan pantai Kabupaten Kepulauan Sangihe. Tetapi komoditi hasil laut tersebut biasanya hanya tertangkap tanpa sengaja (by catch) dengan jaring insang dasar. Sebenarnya telah ada alat tangkap bubu khusus untuk kepiting bakau dan rajungan, tetapi belum dikenal oleh nelayan lokal. Pemberian ekstrak minyak cumi pada umpan, diduga dapat meningkatkan kemampuan tangkap dari bubu kepiting bakau dan rajungan. Penelitian ini bertujuan untuk mempelajari pengaruh ekstrak minyak cumi pada umpan bubu terhadap hasil tangkapan kepiting bakau dan rajungan, dan mengidentifikasi jenis-jenis biota yang tertangkap. Penelitian ini dilakukan di perairan Malise Kecamatan Tabukan Tengah, Kabupaten Kepulauan Sangihe; selama 2 minggu pada bulan September 2015; yang didasarkan pada metode eksperimental. Enam unit bubu dioperasikan selama sepuluh trip untuk mengumpulkan data; di mana tiga unit menggunakan umpan ikan layang yang disuntikan ekstrak minyak cumi, dan tiga unit lainnya hanya menggunakan umpan ikan laying tanpa ekstrak; dan data dianalisis dengan uji t. Tangkapan total berjumlah 142 ekor (135 ekor kepiting bakau dan 7 ekor rajungan); di mana 86 ekor tertangkap dengan umpan layang yang diberi ekstrak minyak cumi, dan 56 ekor tertangkap dengan umpan tanpa ekstrak. Hasil analisis menunjukkan bahwa penggunaan ekstrak minyak cumi pada umpan bubu, memberikan hasil tangkapan yang sangat berbeda dibandingkan dengan umpan tanpa ekstrak minyak cumi.
\end{abstract}

Kata-kata kunci: kepiting bakau, rajungan, umpan bubu, ekstrak minyak cumi, Sangihe

\footnotetext{
*Penulis untuk penyuratan; email: maichelpananggung@gmail.com
} 


\section{PENDAHULUAN}

Kepiting bakau (Scylla serrata) dan rajungan (Portunus pelagicus) di perairan pantai Sulawesi Utara biasanya tertangkap tanpa sengaja (by catch) dengan jarring insang dasar. Sebenarnya telah ada alat tangkap bubu khusus untuk kepiting bakau dan rajungan, tetapi belum dikenal oleh nelayannelayan yang tinggal di daerah sekitar perairan Malise.

Miler (1990) menyatakan bahwa keberhasilan penangkapan menggunakan bubu dipengaruhi oleh beberapa faktor seperti konstruksi bubu, lama perendaman (soaking time) dan umpan. Umpan merupakan salah satu faktor penting dalam menunjang keberhasilan suatu operasi penangkapan ikan, khususnya untuk alat tangkap pasif seperti bubu dan pancing (Subani dan Barus 1989). Alat tangkap bubu biasanya menggunakan umpan alami berupa ikan, karena mudah di dapat dan masih memiliki kesegaran yang baik (Ramdani, 2007).

Fokus utama untuk memahami proses tertangkapnya ikan adalah tertuju pada umpan dan bagaimana komposisi kimianya yang merangsang ikan untuk makan; kemudian penglihatan dan penampilan fisik yang dapat menstimulasi respon positif atau negatif terhadap alat tangkap (Reppie, 2010). Pemberian ekstrak berupa minyak cumi pada umpan, diduga dapat meningkatkan kemampuan tangkap dari alat tangkap bubu; namun informasi ilmiah seperti ini, belum banyak tersedia. Oleh karena itu, dipandang perlu untuk melakukan penelitian tentang pengaruh ekstrak minyak cumi pada umpan bubu terhadap hasil tangkapan kepiting bakau dan rajungan.

\section{METODE PENELITIAN}

Penelitian ini dilakukan di perairan Malise Kecamatan Tabukan Tengah, Kabupaten Kepulauan Sangihe. Waktu pelaksanaannya selama 2 minggu pada bulan September 2015. Penelitian ini dikerjakan dengan mengikuti metode eksperimental, yaitu suatu rancangan percobaan yang diujicobakan untuk memperoleh informasi tentang persoalan yang sedang diteliti. Lewat metode ini dapat diperoleh informasi yang diperlukan dalam melakukan penelitian tentang persoalan yang akan dibahas sehingga akan dihasilkan suatu kesimpulan sesuai dengan tujuan penelitian (Sudjana, 1994).

Teknik pengumpulan data dilakukan dengan cara mengoperasikan 6 unit bubu di perairan Malise Kecamatan Tabukan Tengah selama 10 trip. Umpan yang digunakan adalah ikan layang, yang dimasukkan per ekor ke dalam setiap unit bubu.Tiga bubu menggunakan umpan ikan layang yang diberi ekstrak minyak cumi $5 \mathrm{cc}$, sedangkan 3 unit bubu lainnya hanya menggunakan umpan ikan layang tanpa ekstrak minyak cumi. Kedalaman perairan daerah operasi penangkapan sekitar $3-6$ $\mathrm{m}$; dan masing-masing bubu ditempatkan pada jarak sekitar $10 \mathrm{~m}$. Penurunan alat tangkap bubu dilakukan pada sore hari sekitar jam 18.00, kemudian diangkat pada keesokan harinya sekitar jam 06.00 pagi. Hasil tangkapan bubu pada setiap pengamatan diidentifikasi, diukur dan dicatat berdasarkan masing-masing perlakuan.

Untuk memenuhi persyaratan analisis dalam menarik kesimpulan, maka dirumuskan hipotesis sebagai berikut :

$\mathrm{H}_{0}=$ Penggunaan ekstrak minyak cumi (cisabu) pada umpan bubu tidak berbeda nyata terhadap hasil tangkapan kepiting bakau dan rajungan;

$\mathrm{H}_{1}=$ Penggunaan ekstrak minyak cumi (cisabu) pada umpan bubu berbeda nyata terhadap hasil tangkapan kepiting bakau dan rajungan.

$\mathrm{H}_{0}$ diterima $\left(\mathrm{H}_{1}\right.$ ditolak) apabila $\mathrm{t}_{\text {hitung }} \leq \mathrm{t}_{\text {tabel }}$, sebaliknya $\mathrm{H}_{0}$ ditolak $\left(\mathrm{H}_{1}\right.$ diterima) apabila $\mathrm{t}_{\text {hitung }}$ $>t_{\text {tabel. }}$. Selanjutnya $t_{\text {hitung }}$ dikerjakan menggunakan analisis perbandingan nilai tengah contoh pengamatan berpasangan (Steel and Torrie, 1989), dengan rumusan:

$$
t=\frac{\bar{X}-\bar{Y}}{S_{\bar{D}}}
$$

$$
\begin{aligned}
& S_{\bar{D}}=\frac{\sum D^{2}-\left(\sum D\right)^{2} / n}{n-1} \\
& t=\frac{\bar{X}-\bar{Y}}{\sqrt{\frac{\sum D^{2}-\left(\sum D\right)^{2} / n}{n-1}}}
\end{aligned}
$$

di mana

$$
\begin{aligned}
\bar{X}= & \text { rata-rata tangkapan bubu dengan umpan } \\
& \text { berekstrak } \\
\bar{Y}= & \text { rata-rata tangkapan bubu dengan umpan } \\
& \text { tanpa ekstrak } \\
D= & \mathrm{X}-\mathrm{Y} \\
n= & \text { jumlah trip operasi penangkapan }
\end{aligned}
$$




\section{HASIL DAN PEMBAHASAN}

\section{Hasil tangkapan}

Operasi penangkapan yang dilakukan sebanyak 10 trip dengan hasil tangkapan yang diperoleh sebanyak 142 ekor kepiting; yang terdiri dari 135 ekor kepiting bakau dan 7 ekor rajungan. Selanjutnya pada perlakuan bubu dengan umpan berekstrak minyak cumi, tertangkap 86 ekor kepiting yang terdiri dari 81 ekor kepiting bakau dan 5 ekor rajungan. Sedangkan pada bubu berumpan tanpa ekstrak tertangkap 56 ekor kepiting, yang terdiri dari 54 ekor kepiting bakau dan 2 ekor rajungan. Sebaran hasil tangkapan menurut perlakuan disajikan dalamTabel 1.

\section{Hasil analisis}

Untuk kepentingan analisis uji $t$, maka data dalam Tabel 1 disederhanakan menjadi seperti Tabel 2, kemudian dianalisis lebih lanjut.

Tabel 1.Jumlah hasil tangkapan (ekor) bubu menurut perlakuan.

\begin{tabular}{|c|c|c|c|c|c|c|c|c|}
\hline \multirow{3}{*}{$\begin{array}{c}\text { Trip } \\
\text { operasi }\end{array}$} & \multicolumn{8}{|c|}{ PERLAKUAN UMPAN } \\
\hline & \multicolumn{4}{|c|}{ Umpan berek strak } & \multicolumn{4}{|c|}{ Umpan tanpa ekstrak } \\
\hline & 1 & 2 & 3 & $T$ & 1 & 2 & 3 & $T$ \\
\hline 1 & 2 & 3 & 3 & 8 & 2 & 2 & 1 & 5 \\
\hline 2 & 3 & 3 & 2 & 8 & 2 & 2 & 2 & 6 \\
\hline 3 & 4 & 3 & 3 & 10 & 3 & 2 & 2 & 7 \\
\hline 4 & 3 & 2 & 3 & 8 & 2 & 2 & 1 & 5 \\
\hline 5 & 5 & 2 & 3 & 10 & 3 & 2 & 2 & 7 \\
\hline 6 & 2 & 3 & 3 & 8 & 2 & 1 & 2 & 5 \\
\hline 7 & 3 & 4 & 3 & 10 & 2 & 3 & 2 & 7 \\
\hline 8 & 2 & 3 & 2 & 7 & 1 & 2 & 2 & 5 \\
\hline 9 & 4 & 2 & 3 & 9 & 2 & 1 & 2 & 5 \\
\hline 10 & 3 & 3 & 2 & 8 & 2 & 1 & 1 & 4 \\
\hline Jumlah & 31 & 28 & 27 & 86 & 21 & 18 & 17 & 56 \\
\hline Jumlah total & \multicolumn{8}{|c|}{142 ekor } \\
\hline
\end{tabular}

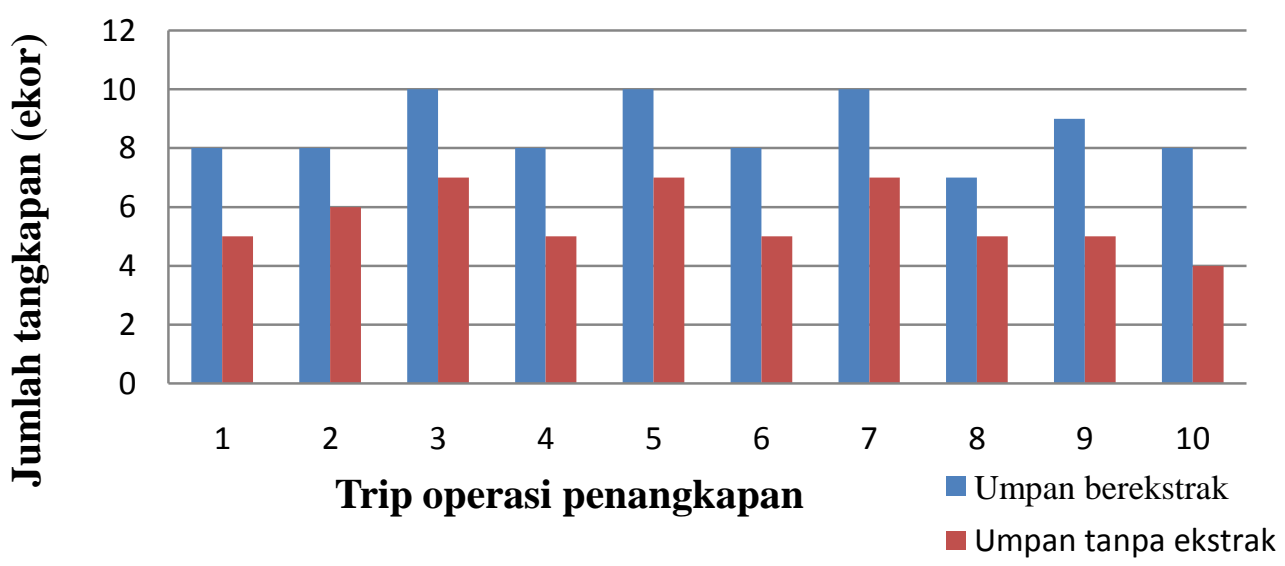

Gambar 1. Sebaran hasil tangkapan bubu berdasarkan perlakuan. 
M.A. Pananggung dkk.

Tabel 2. Analisis perbandingan nilai tengah contoh pengamatan terhadap hasil tangkapan bubu

\begin{tabular}{ccccc}
\hline Trip & Bubu Berekstrak (X) & $\begin{array}{c}\text { Bubu Tanpa Ekstrak } \\
(\mathrm{Y})\end{array}$ & $\mathrm{D}(\mathrm{X}-\mathrm{Y})$ & $\mathrm{D}^{2}$ \\
\hline 1 & 8 & 5 & 3 & 9 \\
2 & 8 & 6 & 2 & 4 \\
3 & 10 & 7 & 3 & 9 \\
4 & 8 & 5 & 3 & 9 \\
5 & 10 & 7 & 3 & 9 \\
6 & 8 & 5 & 3 & 9 \\
7 & 10 & 7 & 3 & 9 \\
8 & 7 & 5 & 2 & 4 \\
9 & 9 & 5 & 4 & 16 \\
10 & 8 & 4 & 4 & 16 \\
\hline Total & 86 & 56 & 30 & 94 \\
\hline Rataan & 8.6 & 5.6 & & \\
\hline Taraf nyata $(\alpha)=5 \%(0,05)$, nilai $\mathrm{t}_{\text {tabel }}$ dengan derajat bebas $(\mathrm{db})=\mathrm{n}-1=9, \mathrm{t}_{0,05: 9}=2,262, \mathrm{t}_{0,01 ; 9}=3,250$
\end{tabular}

Hasil analisis menunjukan bahwa $\mathrm{t}_{\text {hitung }}=4,5>\mathrm{t}_{\text {tabel }}$ $(0,01 ; 9)=3,250$; sehingga menolak $\mathrm{H}_{0}$ dan menerima $\mathrm{H}_{1}$, dimana hal ini menjelaskan bahwa penggunaan ekstrak minyak cumi pada umpan bubu memberikan hasil tangkapan yang sangat berbeda dibandingkan dengan umpan tanpa ekstrak minyak cumi.

\section{Pembahasan}

Informasi ilmiah tentang penggunaan ekstrak kimia pada umpan bubu untuk menangkap kepiting bakau dan rajungan belum tersedia; tetapi studi-studi tentang pemberian rangsangan kimiawi pada umpan, telah dilakukan sejak lama oleh beberapa ahli (Labaro dkk., 2008); antara lain Tester dkk., (1954) dalam Gunarso (1985), yang mencoba menarik perhatian ikan dengan menggunakan aroma bau pada perikanan long line. Kemudian Gunarso (1985) juga telah melakukan percobaan sejumlah umpan buatan dari nilon yang dicelup ke dalam minyak cumi-cumi dan diperlakukan pada perikanan long line. Namun hasilnya masih belum belum memuaskan sehingga belum dapat diterapkan pada perikanan long line. Teknik pemberian ekstrak minyak cumi pada umpan untuk bubu ternyata memberikan hasil yang lebih baik daripada umpan yang sama tanpa ekstrak terhadap hasil tangkapan kepiting bakau dan rajungan sehingga layak diterapkan pada masyarakat nelayan bubu yang biasanya menggunakan umpan moluska mangrove (telescopium) tanpa ekstrak. Pernyataan ini ditunjang pula oleh Labaro dkk. (2008), bahwa pemberian ekstrak cisabu pada umpan pancing ulur tuna dapat meningkatkan hasil tangkapan, dibandingkan dengan umpan tanpa ekstrak. Mainake (2014) juga memberikan kesimpulan bahwa umpan bubu paralon yang diberi ekstrak minyak tuna menghasilkan tangkapan yang lebih baik dibandingkan dengan umpan tanpa ekstrak.

Kepiting bakau yang tertangkap pada perairan Malise belum layak untuk ditangkap karena ukuran panjang karapasnya tidak memenuhi syarat untuk ditangkap sedangkan untuk rajungan sudah memenuhi syarat untuk ditangkap dan diperjualbelikan. Berdasarkan pengamatan di lokasi penangkapan, kepiting bakau di perairan Malise mengalami overfishing karena penangkapannya selalu dilakukan setiap hari, sedangkan rajungan tertangkap pada jaring yang digunakan nelayan untuk menangkap ikan dan hanya dimanfaatkan sebagai hasil tangkapan sampingan.

Menurut Hill (1982), ukuran kepiting bakau yang legal untuk di perdagangkan memiliki panjang karapas rata-rata $>15 \mathrm{~cm}$. Juga Menteri Kelautan dan Perikanan (2015) mengemukakan bahwa bulan Januari 2016 sampai dengan seterusnya ukuran dan berat yang boleh di tangkap dan diperjualbelikan yaitu: kepiting (scylla spp) dengan ukuran lebar karapas $>15 \mathrm{~cm}$. Sedangkan untuk rajungan menurut Kangas (2000) bahwa ukuran legal yang berlaku di Australia, yaitu rajungan yang mempunyai ukuran lebar karapas di atas $11 \mathrm{~cm}$. Menteri Kelautan dan Perikanan (2015) juga mengemukakan bahwa pada bulan Januari 2016 dan seterusnya ukuran dan berat yang boleh di tangkap dan di perjual belikan yaitu: rajungan (portunus spp) dengan ukuran lebar karapas $>10 \mathrm{~cm}$. 


\section{KESIMPULAN}

Penambahan ekstrak minyak cumi pada umpan bubu memberikan hasil tangkapan kepiting bakau yang lebih baik (86 ekor) kepiting yang terdiri dari 81 ekor kepiting bakau dan 5 ekor rajungan, dibandingkan bubu berumpan tanpa ekstrak minyak cumi 56 ekor kepiting, yang terdiri dari 54 ekor kepiting bakau dan 2 ekor rajungan.

\section{DAFTAR PUSTAKA}

Gunarso, W. 1985. Suatu pengantar tentang tingkah laku ikan terutama dalam hubungannya dengan alat tangkap, metode dan taktik penangkapan. Fakultas Perikanan Institut Pertanian Bogor.

Hill, B.J. 1982. The Queensland mud crab fishery. Queensland Fisheries Information Series F18201. Fisheries Research Branch. Qld. Dep. of Primary Industies. Queensland Australia.
Kangas, M.I. 2000. Synopsis of the biology and exploitation of the blue swimmer crab, Portunus pelagicus Linnaeus, in Western Australia fisheries. Western Australia Fisheries Ressearch Report No. 121. Western Australia, Perth.

Keputusan Menteri Kelautan dan Perikanan RI. 2011. Nomor Kep.18/MEN/2011 tentang Pedoman umum minapolitan.

Labaro, L., E.M. Katiandagho, E. Reppie, dan J. Budiman. 2008. Pengaruh larutan minyak cumi terhadap hasil tangkapan pancing ulur tuna di perairan sekitar Pulau Batang Dua. Prosiding Konferensi Nasional VI, Pengelolaan Sumberdaya Pesisir dan Lautan.

Mainake, J. 2014. Pengaruh tambahan ekstrak minyak tuna pada umpan bubu paralon terhaap hasil tangkapan ikanikan karang. Di unggah 8 Novembar 2015, dari http://download.portalgaruda.org/article.php?

Reppie, E. 2010. Pengaruh minyak cumi pada umpan bubu dasar terhadap hasil tangkapan ikan-ikan karang. Jurnal Perikanan dan KelautanTropis VI(3): 140-143.

Steel, R.G.D. dan J.H. Torrie, 1989. Principles and Procedures of Statistics. 2nd ed. Mc Graw Hill International Book Company, London.

Sudjana, 1994. Desain dan Analisis Eksperimen. Edisi III. Tarsito, Bandung. 